\title{
Weak Self-Efficacy Versus Strong Self-Inefficacy: A Comment on the Conceptual Difference
}

\author{
Michael K. Ponton \\ Dept. of Higher Education and Learning Technologies, Texas A\&M University-Commerce \\ P.O. Box 3011, Commerce, Texas 75429, United States \\ E-mail: Michael.Ponton@tamuc.edu
}

Received: January 24, 2020 Accepted: March 4, $2021 \quad$ Published: March 22, 2021

doi:10.5296/ijssr.v9i2.18244 URL: https://doi.org/10.5296/ijssr.v9i2.18244

\begin{abstract}
The purpose of this article is to discuss the conceptual difference between weak self-efficacy (i.e., a weak perception of ability) and strong self-inefficacy (i.e., a strong perception of inability). The difference between the two rests with the former being due to little efficacy-enhancing information and the latter being due to a great deal of efficacy-diminishing information. The importance of this distinction is (a) the former is more changeable, and (b) many current instruments do not address this distinction. Because of the importance of self-efficacy in cognitive motivation, being able to conceptualize and measure this distinction is inherently necessary to create proper interventions (i.e., efficacy enhancing methods) that facilitate achievement and accurate theorizing.
\end{abstract}

Keywords: self-efficacy, self-inefficacy, social cognitive theory 


\section{Introduction}

Self-efficacy refers to a person's perceived ability to successfully execute a given action (Bandura, 1997). As such, self-efficacy is a domain-specific assessment as one's perceived ability varies considerably between activities. For example, a person can perceive an ability to design a computer, solve a calculus problem, or hit a golf ball as well as perceive an ability to learn to do any one of these activities or persist in doing any one of these activities in the face of failures and obstacles. As a perception, self-efficacy is not an objective measure of actual ability as even objective measures of successful performances can be subjectively interpreted in either efficacy strengthening or weakening ways.

Self-efficacy has been shown to be an important mediating factor in cognitive motivation (Bandura, 1997). In the pursuit of a desirable outcome (e.g., pleasure, money, or social acceptance), a person intentionally engages in an activity that is anticipated will lead to this outcome when the activity is successfully performed; thus, he or she will not choose to engage in a futile endeavor but rather choose an activity in which there is a perceived likelihood of success. As such, a person compares self-efficacy strength between activities that have a perceived causal influence to the desired outcome and then chooses an activity to pursue; thus, self-efficacy mediates the path from the determination of a desirable outcome to the motivation to engage in a particular activity.

Similarly, percepts of efficacy in the face of failures influence the decision to persist in a given activity. This efficacy assessment may be the perceived ability to successfully perform the given activity itself or the perceived ability to successfully learn how to perform the given activity (Ponton, Carr, \& Wiggers, 2014); however, in either case, it is still an efficacy assessment that influences perseverant behavior.

Because self-efficacy has been shown to have predictive and explanatory power in understanding activity choice, motivation, perseverance, and resultant successful performances (Bandura, 1997) in numerous domains (cf. Bandura, 1995, 1997; Pajares \& Urdan, 2006), an accurate understanding of this construct is essential to further instrument development and theory building. The premise of this article is that there is a conceptual difference between weak self-efficacy (i.e., a weak perception of ability) and strong self-inefficacy (i.e., a strong perception of inability) that has not been adequately addressed in the literature. As a result, current instruments may be deficient in their designs to differentiate these two constructs and, thus, not providing the data needed for completely understanding the role of self-efficacy in human functioning.

\section{Self-Efficacy}

Social cognitive theory (Bandura, 1986) characterizes people as agentic beings capable of engaging in intentional activities. Using forethought, desirable outcomes are considered and plans for action created; after this, self-regulation enables a person to work toward desired goals; finally, self-reflection allows a person to determine how well actual outcomes reflect desired ones and to create meaning regarding the performance as well as oneself. Using resultant meanings, forethought is again enlisted to direct future action. 
"Among the mechanisms of human agency, none is more central or pervasive than belief of personal efficacy... Unless people believe they can produce desired effects by their actions, they have little incentive to act, or to persevere in the face of difficulties" (Bandura, 2006b, p. 170). Self-efficacy refers to a person's perception of his or her ability "to organize and execute the courses of action required to produce given attainments" (Bandura, 1997, p. 3).

People are not born with a sense of personal efficacy in various activities; rather, people develop a sense of their capabilities by reflecting upon sources of information from their experiences as well as from their environments. Even with ostensibly similar information, people can engage in differential meaning making and, thus, use similar information in either efficacy weakening or strengthening ways.

For example, the most authentic source of efficacy information is an enactive mastery experience (Bandura, 1997), which refers to an actual performance of the activity under consideration. For example, the self-assessments of cake baking, tree climbing, and algebra problem solving capabilities are most authentically informed by previous cake baking, tree climbing, and algebra problem solving performances, respectively, and whether or not such performances were successes or failures. However, whether or not successes or failures are attributed by the individual to himself or herself or, rather, to some external factor (e.g., helpful others or facilitative conditions) can create variation in how individuals interpret similar successes or failures in ways that strengthen, weaken, or leave unchanged percepts of efficacy.

The variation between individuals regarding conceptions of ability as either static (resistant to change) or dynamic (changeable) can also cause variation in efficacy building due to interpretations of effort expenditures (Bandura, 1997). When a performance requires a great deal of effort, a conceptualization that ability is static supports the notion that requisite ability is lacking thereby weakening self-efficacy; however, a dynamic conception of ability allows a person to believe that great effort leads to ability development thereby strengthening self-efficacy.

Negative physiological and emotive stresses induced by performances also vary in their effects on self-efficacy due to the static versus dynamic conceptions of ability (Bandura, 1997). When a performance creates stress (e.g., physical pain), the static conception of ability suggests that requisite ability is lacking; however, a dynamic conception of ability can lead to the person believing that such stress coincides with ability development thereby strengthening self-efficacy as well as anticipation that, with ability development, future performances will yield less stress.

Mastery experiences and physiological/emotive arousals produce efficacy information as a result of a person's performances. In contrast, there are two sources of efficacy information that come from the environment: vicarious experiences and verbal persuasion (Bandura, 1997). When a person (i.e., the observer) witnesses another person (i.e., the model) engage in a successful performance and the model is perceived by the observer as similar to the observer in ways relevant to the performance, the observer's self-efficacy may be strengthened vicariously consistent with the often used phrase "if that person can do it, so can 
I." In addition, a person's efficacy can be strengthened when a credible person (i.e., the persuader) provides encouragement to a person (i.e., the receiver) that he or she has the requisite capability. Although such encouragement is often transmitted verbally, it can be communicated by any means. The essential factor in whether or not such information strengthens the receiver's self-efficacy is the degree to which the persuader's assessment is deemed credible by the receiver.

\section{Weak Self-Efficacy and Strong Self-Inefficacy}

In the literature, weak self-efficacy (sometimes referred to as low self-efficacy) and self-inefficacy are synonymously-used phrases that describe a perception of inability. Note, however, that perception of inability can be derived from two very different conditions: (a) very little information that supports a strong personal appraisal of ability, or (b) a great deal of information that supports a strong personal appraisal of inability. The proposed position in this article is that a weak sense of efficacy due to a lack of efficacy-enhancing information is a completely different appraisal than a strong sense of inefficacy due to a great deal of efficacy-diminishing information. Note that the efficacy appraisal itself is likely more accurate in the strong self-inefficacy condition (i.e., more congruent with actual inability) because it suggests the person has greater knowledge regarding the targeted performance, requisite subskills, and associated impediments than the weak self-efficacy condition that suggests little if any relevant knowledge.

The reason for the distinction between these two conditions - weak self-efficacy and strong self-inefficacy - is due to the manner in which people develop self-knowledge. Bandura (1997) stated the following: "People do not approach tasks devoid of any notion about themselves.... Through transactional experiences, they evolve a structured self-system with a rich schematic network.... The weight people give to new experiences and how they reconstruct them in memory also depends, in part, on the nature and strength of the self-beliefs into which those experiences must be integrated.... Efficacy beliefs are thus both products and constructors of experiences" (pp. 81-82).

People make judgments about themselves in light of current judgments derived from their experiences. New experiences are, thus, interpreted through an existing cognitive lens and self-knowledge integrated into existing self-schema. When experiences are minimal, self-judgments are certainly made but reflect tenuous appraisals; when experiences are extensive, again self-judgments are made but reflect substantive appraisals. This line of theorizing suggests that weak self-efficacy is likely more temporally unstable and, thus, more changeable than strong self-inefficacy. Due to the importance of a strong sense of efficacy in human achievement, it is inherently important to understand the conditions upon which efficacy can be strengthened thereby positively influencing performance.

\subsection{Instrumentation Issue: An Example}

Bandura (2001, 2006a) provided a primer on how to construct self-efficacy scales. As previously discussed, self-efficacy is a domain specific construct; thus, "scales of perceived self-efficacy must be tailored to the particular domain of functioning that is the object of 
interest" (Bandura, 2006a, pp. 307-308) in contrast to general scales that offer "limited explanatory and predictive value" (p. 307). In addition, scales should be designed to measure perceived ability in light of impediments; "if there are no obstacles to overcome, the activity is easily performable and everyone is highly efficacious" (Bandura, 2006a, p. 311). "Perceived self-efficacy is conceptualized as perceived operative capability. It is concerned not with what one has [in terms of a repertoire of rudimentary skills] but with belief in what one can do with whatever resources one can muster" (Bandura, 2007, p. 646).

Based upon the Exercise Self-Efficacy Scale (Bandura, 2001), Ponton, Derrick, Hall, Rhea, and Carr (2005; also available in Ponton et al., 2016) developed the Appraisal of Learner Autonomy (ALA) that measures a person's self-efficacy to engage in autonomous learning. As this instrument expressly incorporates Bandura's (2001, 2006a) design guidelines, it represents a suitable example for analysis.

The ALA offers the following prompt: "In each of the following situations, please rate how sure you are that you can get yourself to participate in a learning activity when nobody else requires you to do so"; one of the nine presented impediment situations is "when visitors are present" (Ponton et al., 2016, p. 183). The ALA and this specific impediment is offered as a typical example of a self-efficacy instrument and item, respectively.

The response scale ranges from cannot do at all to certain can do. A response that favors the cannot do at all end of the scale can reflect the following distinct scenarios:

1) Very few experiences that led to successfully (a) engaging in autonomous learning, (b) avoiding the distraction of visitors, or (c) engaging in autonomous learning while avoiding the distraction of visitors; or

2) Very many experiences that led to unsuccessfully (a) engaging in autonomous learning, (b) avoiding the distraction of visitors, or (c) engaging in autonomous learning while avoiding the distraction of visitors.

The resultant response (i.e., cannot do at all region of the scale) is entirely accurate in both scenarios, but the response is unable to nuance two very different human conditions that correspond to two very different constructs.

A weak belief is based upon the absence of information whereas a strong belief is based upon the presence of information. A strong belief is less likely altered when presented with contrary evidence (i.e., information that is incongruent with the belief) as such evidence is often rejected; however, a weak belief is more likely altered when presented with contrary evidence (cf. Bandura, 1997). Self-efficacy theorizing and associated instruments must address this important distinction between weak self-efficacy (i.e., a weak perception of ability based upon the absence of information) and strong self-inefficacy (i.e., a strong perception of inability based upon the presence of information) in order to accurately characterize two very different human conditions that represent two very different descriptions of human functioning and opportunities for change. 


\section{Ml Macrothink}

\section{Conclusions}

Since Bandura's seminal work in 1977, self-efficacy has been shown to be an essential construct in understanding the factors (e.g., choice, motivation, perseverance, anxiety, and self-concept) that influence human performance. The importance of psychological theorizing rests in its ability to affect human functioning in health-promoting ways; thus, accurate theorizing supported by valid research is essential.

The purpose of this article is to argue that there is an important conceptual difference between weak self-efficacy and strong self-inefficacy that has not been addressed either theoretically or instrumentally. This deficiency in consideration suggests that our understanding of self-efficacy is not entirely accurate, and efficacy-building strategies may be misapplied in these two distinct situations. As such, future research and theorizing should work to capture this important distinction thereby increasing the explanatory, predictive, and interventional power of efficacy-strengthening strategies.

\section{References}

Bandura, A. (1977). Self-efficacy: Toward a unifying theory of behavioral change. Psychological Review, 84(2), 191-215. https://doi.org/10.1037/0033-295X.84.2.191

Bandura, A. (1986). Social foundations of thought and action: A social cognitive theory. Englewood Cliffs, NJ: Prentice Hall.

Bandura, A. (Ed.). (1995). Self-efficacy in changing societies. Cambridge, UK: Cambridge University Press. https://doi.org/10.1017/CBO9780511527692

Bandura, A. (1997). Self-efficacy: The exercise of control. New York, NY: W. H. Freeman and Company.

Bandura, A. (2001). Guide for constructing self-efficacy scales. Unpublished manuscript, Department of Psychology, Stanford University, Stanford, CA.

Bandura, A. (2006a). Guide for constructing self-efficacy scales. In F. Pajares \& T. Urdan (Eds.), Self-efficacy beliefs of adolescents (pp. 307-337). Greenwich, CT: Information Age.

Bandura, A. (2006b). Toward a psychology of human agency. Perspectives on Psychological Science, 1(2), 164-180. https://doi.org/10.1111/j.1745-6916.2006.00011.x

Bandura, A. (2007). Much ado over a faulty conception of perceived self-efficacy grounded in faulty experimentation. Journal of Social and Clinical Psychology, 26(6), 641-658. https://doi.org/10.1521/jscp.2007.26.6.641

Pajares, F., \& Urdan, T. (Eds.). (2006). Self-efficacy beliefs of adolescents. Greenwich, CT: Information Age.

Ponton, M. K., Carr, P. B., \& Wiggers, N. R. (2014). Self-efficacy to do or self-efficacy to learn to do: A study related to perseverance. International Journal of Self-Directed Learning, 11(1), 29-40. Retrieved from http:/www.sdlglobal.com/journals 


\section{Macrothink}

Ponton, M. K., Derrick, M. G., Hall, J. M., Rhea, N. E., \& Carr, P. B. (2005). The relationship between self-efficacy and autonomous learning: The development of new instrumentation. International Journal of Self-Directed Learning, 2(1), 50-61. Retrieved from http://www.sdlglobal.com/journals

Ponton, M. K., Derrick, M. G., Hall, J. M., Rhea, N. E., \& Carr, P. B. (2016). The relationship between self-efficacy and autonomous learning: The development of new instrumentation. In M. K. Ponton \& P. B. Carr (Eds.), Autonomous and self-directed learning: Agentic perspectives (pp. 167-183). Chesapeake, VA: Watertree Press.

\section{Copyrights}

Copyright for this article is retained by the author(s), with first publication rights granted to the journal.

This is an open-access article distributed under the terms and conditions of the Creative Commons Attribution license (http://creativecommons.org/licenses/by/4.0/). 